\title{
Reducing the donor site morbidity in radial forearm free flaps by utilizing a narrow radial forearm free flap
}

\author{
Safdar Ali Shaikh ${ }^{1}$, Amber Bawa ${ }^{1}$, Noman Shahzad ${ }^{2}$, Zara Yousufzai ${ }^{1}$, Muhammad Shahab Ghani ${ }^{1}$ \\ ${ }^{1}$ Department of Plastic Surgery, Liaquat National Hospital, Karachi; ${ }^{2}$ Department of General Surgery, Aga Khan University Hospital, \\ Karachi, Pakistan
}

Background The radial forearm free flap (RFFF) has remained a leading choice of many plastic surgeons as a fasciocutaneous flap due to its versatility, pedicle length, and simple elevation technique. However, donor site morbidity has led many reconstructive surgeons to limit their use of the RFFF and to use other flaps instead. We propose that using a narrow RFFF (nRFFF) decreases the aesthetic and functional morbidity of the donor site.

Methods We report our experiences with the nRFFF from April 2012 through May 2015 at the Department of Plastic, Reconstructive, and Hand Surgery at Liaquat National Hospital, Karachi. The donor defects were closed primarily. The Stony Brook Scar Evaluation Scale and comparison with the contralateral hand were used to assess aesthetic and functional outcomes, respectively.

Results A total of 24 patients underwent nRFFF procedures during the study period. The donor arm showed excellent motor function in 22 cases (91.7\%), and very good function in the remaining two cases $(8.3 \%)$. The aesthetic outcomes were excellent in four patients (16.6\%), very good in eight patients (33.3\%), good in 10 patients (41.6\%), and fair in two patients $(8.3 \%)$ who developed a hypertrophic scar. All flaps were successful and there were no cases of partial or complete loss.

Conclusions For small to medium-sized soft tissue defects, the nRFFF had acceptable outcomes due to its thinness, pliability, and major reduction in donor site aesthetic and functional morbidity.

Keywords Free tissue flaps / Reconstructive surgery / Cicatrix, hypertrophic

Received: 30 Jan $2018 \bullet$ Revised: 2 May $2018 \bullet$ Accepted: 27 May 2018

pISSN: 2234-6163 • elSSN: 2234-6171 • https://doi.org/10.5999/aps.2018.00115• Arch Plast Surg 2018;45:345-350
Correspondence: Noman Shahzad Department of General Surgery, Aga Khan University Hospital, Stadium Road Karachi 74800, Pakistan Tel: +92-30-0883-3313 Fax: +92-21-3493-4294 E-mail:drns01@hotmail.com

\section{INTRODUCTION}

The radial forearm free flap (RFFF) was introduced by Yang et al. [1] in 1981, and it has since become one of the most commonly used free flaps in head and neck reconstructive surgery. Initially, the RFFF was used for wound coverage after the release of skin contracture in burn patients, but it is now indicated for almost all parts of the body, including head and neck, limb, and penile reconstructive surgery [2-7], due to its thinness, pliability, pedicle length, and vessel size [8].

However, although this flap leads to excellent results at the site of reconstruction, it is associated with a worrisome amount of 
donor site morbidity, and its advantages must be balanced against potential complications at the donor site. Variable amounts of cosmetic impairment and objective evidence of restriction of movement and reduction in grip strength at the donor site have been reported [9-16]. Common early complications include wound breakdown and skin graft loss, leading to delayed wound healing and tendon exposure $[17,18]$. Longterm complications include reduced wrist mobility, wrist or hand weakness $[10,18]$, sensory deficits $[14,19]$, persisting pain $[17,19]$, decreased hand dexterity [19], and cosmetic deformity $[17]$ in objective and subjective assessments.

The most common method used to close the donor site is a split-thickness skin graft $[9,17]$. Other methods described in the literature include full-thickness skin grafts from the forearm, inner arm, and abdomen, in addition to the use of tissue expanders, local flaps, or free flaps and primary closure.

The purpose of the current study was to introduce the use of a narrow RFFF (nRFFF) and to assess the aesthetic outcomes of the donor site when closed primarily. We also evaluated the motor function of the donor forearm and hand.

\section{METHODS}

A retrospective study was conducted of patients who presented to our hospital from April 2012 to May 2015. All patients with small to medium-size intraoral defects underwent reconstructions using this flap. The Allen test was performed prior to the

\section{Fig. 1. Long and narrow radial forearm free flap}

(A) Free flap as dissected initially. (B) Flap rolled onto itself.
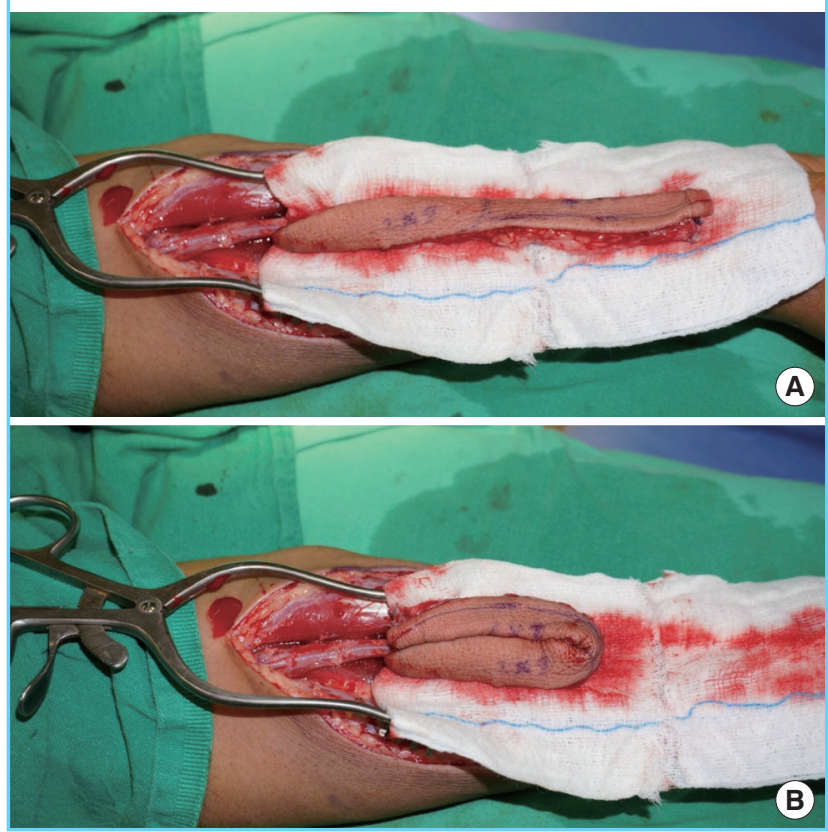

operation to confirm adequate vascularity of the hand via the ulnar artery, with the non-dominant forearm selected as the donor site. If the Allen test showed inadequate perfusion of the hand by the ulnar artery alone, nRFFF was not done. The ideal site was a relatively hairless thin-skinned radial forearm. The pinch test was performed to assess the possibility of primary closure of the donor site. An nRFFF was raised and then rolled onto itself to double its width and halve its length, as shown in Fig. 1 . The pedicle was not physically attached to the proximal half of the flap, as the radial vessels run superficially in the distal half of forearm, giving rise to multiple perforators, while in the proximal half these vessels run deeper and have very few or sometimes no perforators. Therefore, folding the flap did not impact pedicle length. The nRFFF was raised according to the classical technique, starting from the distal forearm and moving to the proximal forearm. The superficial radial nerve was sacrificed, while the superficial venous system was preserved. In most cases, the cephalic vein was traced up to the cubital fossa, preserving its connection to the deep system, so that the vein could be used for the venous anastomosis. The donor site was then closed primarily. Capillary refill was assessed at the time of wound closure, and the wound was closed primarily only if satisfactory capillary refill was demonstrated.

The aesthetic and functional outcomes were recorded at 6 months of follow-up. The aesthetic outcomes were assessed based on the Stony Brook Scar Evaluation Scale (Table 1) [20], and the outcomes were classified into five categories, as shown in Table 2. Functional outcomes were assessed based on the motor grade (1-5), compared to the contralateral normal hand.

The study was conducted following the ethical principles set out in the Declaration of Helsinki. Patients' images presented in

\begin{tabular}{|c|c|}
\hline Scar category & No. of point ${ }^{\text {a) }}$ \\
\hline \multicolumn{2}{|l|}{ Width, mm } \\
\hline$>2$ & 0 \\
\hline$\leq 2$ & 1 \\
\hline \multicolumn{2}{|l|}{ Height } \\
\hline Elevated or depressed in relation to surrounding skin & 0 \\
\hline Flat & 1 \\
\hline \multicolumn{2}{|l|}{ Color } \\
\hline Darker than surrounding skin (red, purple, brown, or black) & 0 \\
\hline Same color or lighter than surrounding skin & 1 \\
\hline \multicolumn{2}{|l|}{ Hatch marks or suture marks } \\
\hline Present & 0 \\
\hline Absent & 1 \\
\hline \multicolumn{2}{|l|}{ Overall appearance } \\
\hline Poor & 0 \\
\hline Good & 1 \\
\hline
\end{tabular}


this manuscript were taken and submitted after the patients provided informed consent for publication of these images.

\section{RESULTS}

A total of 24 cases were performed between April 2012 and

\section{Table 2. Categories of aesthetic outcomes based on the Stony Brook Scar Evaluation Scale score}

\begin{tabular}{|lc|}
\hline Category & Stony Brook Scar Evaluation Scale score \\
\hline Poor & $\leq 1$ \\
Fair & 2 \\
Good & 3 \\
Very good & 4 \\
Excellent & 5 \\
\hline
\end{tabular}

\section{Table 3. Sites of reconstruction}

\begin{tabular}{|lc|}
\hline Sites & No. of cases \\
\hline Intraoral cheek & 15 \\
Tongue+floor of mouth & 4 \\
Palate & 1 \\
Cheek with angle of mouth & 1 \\
Gingivobuccal sulcus & 1 \\
Retromolar fossa & 1 \\
Lower lip & 1 \\
\hline
\end{tabular}

May 2015. Of the study population, 20 (83\%) were males. The participants' mean age was $49.04 \pm 10.07$ years. In all cases, the flap was used to cover defects in the oral cavity. Detailed information about the sites inside the oral cavity is given in Table 3 . The mean flap width was $2.36 \pm 0.41 \mathrm{~cm}$ and the mean length was $13.65 \pm 3.08 \mathrm{~cm}$. Details regarding the flap size and donor defects are provided in Table 4 . All the donor defects were closed primarily except for one patient (case no. 15 in Table 4) who needed a skin graft. Capillary refill after primary closure was not satisfactory in this case.

The aesthetic outcomes were excellent in four patients (16.6\%), very good in eight patients (33.3\%), good in 10 patients (41.6\%), and fair in two patients (8.3\%) who developed a

Table 5. Aesthetic outcomes of the patients according to the Stony Brook Scar Evaluation Scale

\begin{tabular}{|lc|}
\hline Category & Patients \\
\hline Excellent & $4(16.6)$ \\
Very good & $8(33.3)$ \\
Good & $10(41.6)$ \\
Fair & $2(8.3)$ \\
Poor & - \\
Total & $24(100)$ \\
\hline Values are presented as number (\%). & \\
\hline
\end{tabular}

\section{Table 4. Details regarding defect size, flap size, and recipient vessels}

\begin{tabular}{|c|c|c|c|c|c|c|c|}
\hline No. & Sex & $\begin{array}{l}\text { Age } \\
(\mathrm{yr})\end{array}$ & Site & $\begin{array}{l}\text { Defect size } \\
\quad(\mathrm{cm})\end{array}$ & $\begin{array}{l}\text { Flap size } \\
\text { (cm) }\end{array}$ & $\begin{array}{c}\text { Primary site } \\
\text { closed }\end{array}$ & Recipient vessels \\
\hline 1 & Male & 46 & Intraoral cheek & $5 \times 6.5$ & $2.5 \times 13$ & Yes & $\mathrm{FA}+\mathrm{CFV}+\mathrm{EJV}$ \\
\hline 2 & Male & 54 & Intraoral cheek & $6 \times 6$ & $3 \times 12$ & Yes & $\mathrm{STA}+\mathrm{CFV}+\mathrm{EJV}$ \\
\hline 3 & Male & 50 & Palate & $4 \times 4$ & $2 \times 8$ & Yes & STA+IJV \\
\hline 4 & Male & 55 & Tongue & $7 \times 10$ & $3.5 \times 20$ & Yes & $\mathrm{STA}+\mathrm{CFV}+\mathrm{IJV}$ \\
\hline 5 & Male & 50 & Tongue+floor of mouth & $5 \times 5$ & $2.5 \times 10$ & Yes & $F A+I J V+E J V$ \\
\hline 6 & Male & 65 & Intraoral cheek & $5 \times 4.5$ & $2.5 \times 9$ & Yes & $\mathrm{STA}+\mathrm{CFV}$ \\
\hline 7 & Male & 39 & Intraoral cheek & $4 \times 6$ & $2 \times 12$ & Yes & $\mathrm{STA}+\mathrm{CFV}+\mathrm{EJV}$ \\
\hline 8 & Male & 55 & Intraoral cheek & $5 \times 5$ & $2.5 \times 10$ & Yes & $\mathrm{FA}+\mathrm{EJV}+\mathrm{CFV}$ \\
\hline 9 & Female & 58 & Oral mucosa of the cheek and angle of mouth & $5 \times 6.5$ & $2.5 \times 13$ & Yes & $F A+I V J$ \\
\hline 10 & Male & 40 & Intraoral cheek+floor of mouth & $4 \times 9$ & $2 \times 18$ & Yes & $F A+I J V$ \\
\hline 11 & Male & 55 & Intraoral cheek+lip & $4 \times 9$ & $2 \times 18$ & Yes & $F A+I J V$ \\
\hline 12 & Male & 54 & Intraoral cheek & $4 \times 6.5$ & $2 \times 13$ & Yes & STA+IJV+EJV \\
\hline 13 & Male & 35 & Intraoral cheek & $1.5 \times 8$ & $3 \times 16$ & Yes & FA+IJV+EJV \\
\hline 14 & Female & 65 & Intraoral cheek & $5 \times 5$ & $2.5 \times 10$ & Yes & $\mathrm{FA}+\mathrm{IJV}+\mathrm{CFV}$ \\
\hline 15 & Male & 52 & Intraoral cheek & $5 \times 5$ & $2.5 \times 10$ & No & STA+IJV \\
\hline 16 & Male & 51 & Intraoral cheek & $4 \times 8$ & $2 \times 16$ & Yes & $\mathrm{STA}+\mathrm{CFV}+\mathrm{EJV}$ \\
\hline 17 & Female & 53 & Gingivobuccal sulcus & $5 \times 6$ & $2.5 \times 12$ & Yes & STA+CFV+IJV \\
\hline 18 & Female & 34 & Tongue & $4 \times 5$ & $2 \times 10$ & Yes & $F A+I J V$ \\
\hline 19 & Male & 46 & Intraoral cheek & $5 \times 6$ & $2.5 \times 12$ & Yes & $F A+I J V$ \\
\hline 20 & Male & 58 & Intraoral cheek & $4 \times 6$ & $2 \times 12$ & Yes & $\mathrm{FA}+\mathrm{CFV}+\mathrm{EJV}$ \\
\hline 21 & Male & 30 & Intraoral cheek & $4.5 \times 6.5$ & $2 \times 6+2.5 \times 7$ & Yes & $\mathrm{STA}+\mathrm{CFV}$ \\
\hline 22 & Male & 40 & Tongue & $4.5 \times 7$ & $2 \times 7+2.5 \times 7$ & Yes & STA+IJV \\
\hline 23 & Male & 60 & Intraoral cheek & $3.6 \times 7$ & $1.8 \times 14$ & Yes & $F A+I J V$ \\
\hline 24 & Male & 32 & Intraoral cheek & $5 \times 7$ & $2.5 \times 14$ & Yes & $\mathrm{STA}+\mathrm{CFV}+\mathrm{EJV}$ \\
\hline
\end{tabular}


Fig. 2. Cheek carcinoma managed by a nRFFF

(A) Squamous cell carcinoma of the left cheek. (B) Marking of the narrow radial forearm free flap (nRFFF). (C) The nRFFF at 3 months postoperatively. (D) The donor site scar at 3 months postoperatively.
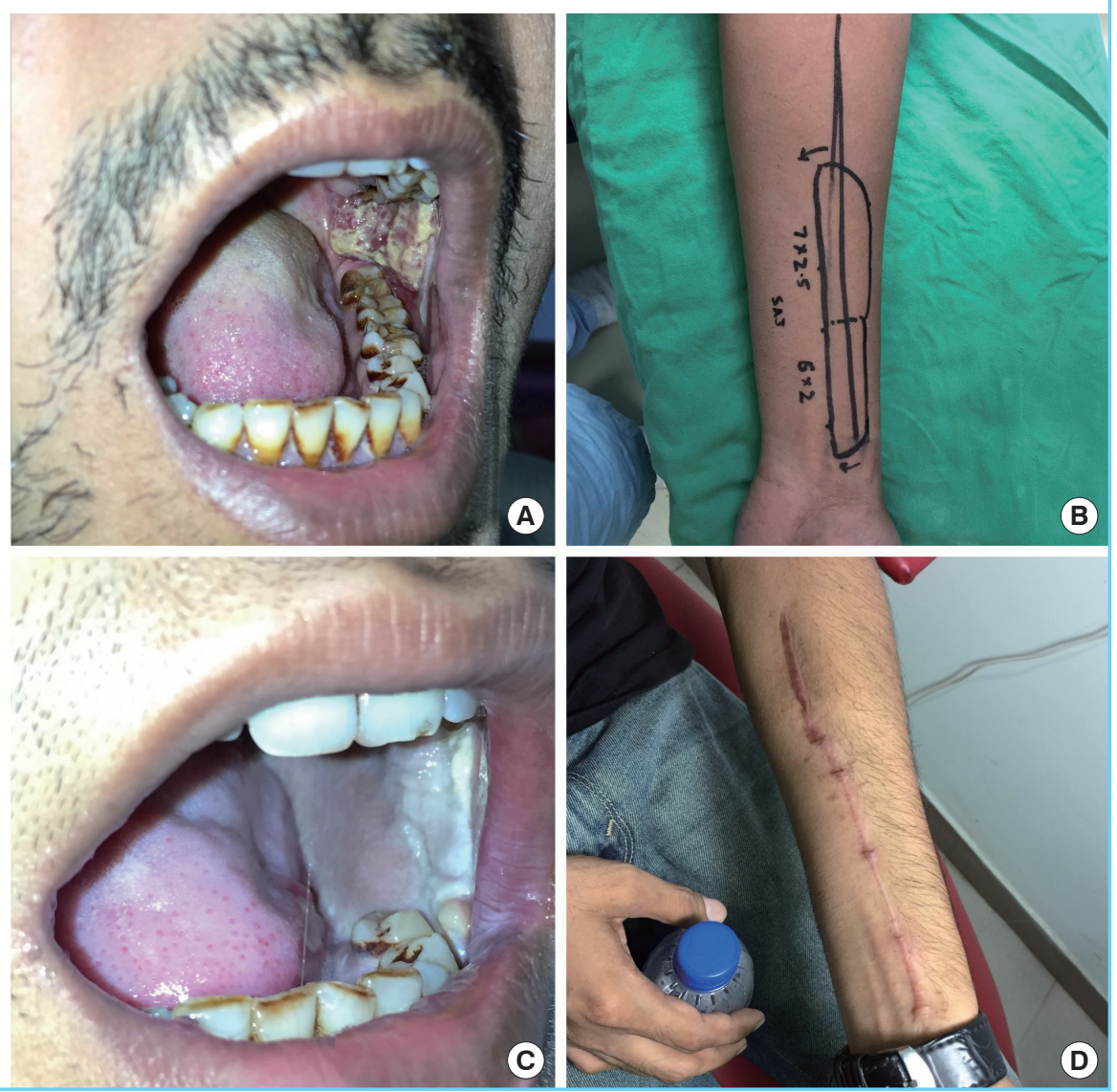

Fig. 3. Tongue carcinoma managed by a nRFFF

(A) Squamous cell carcinoma of the tongue. (B) Marking of the narrow radial forearm free flap (nRFFF). (C) The nRFFF at 2 months postoperatively. (D) The donor site scar after 2 months.
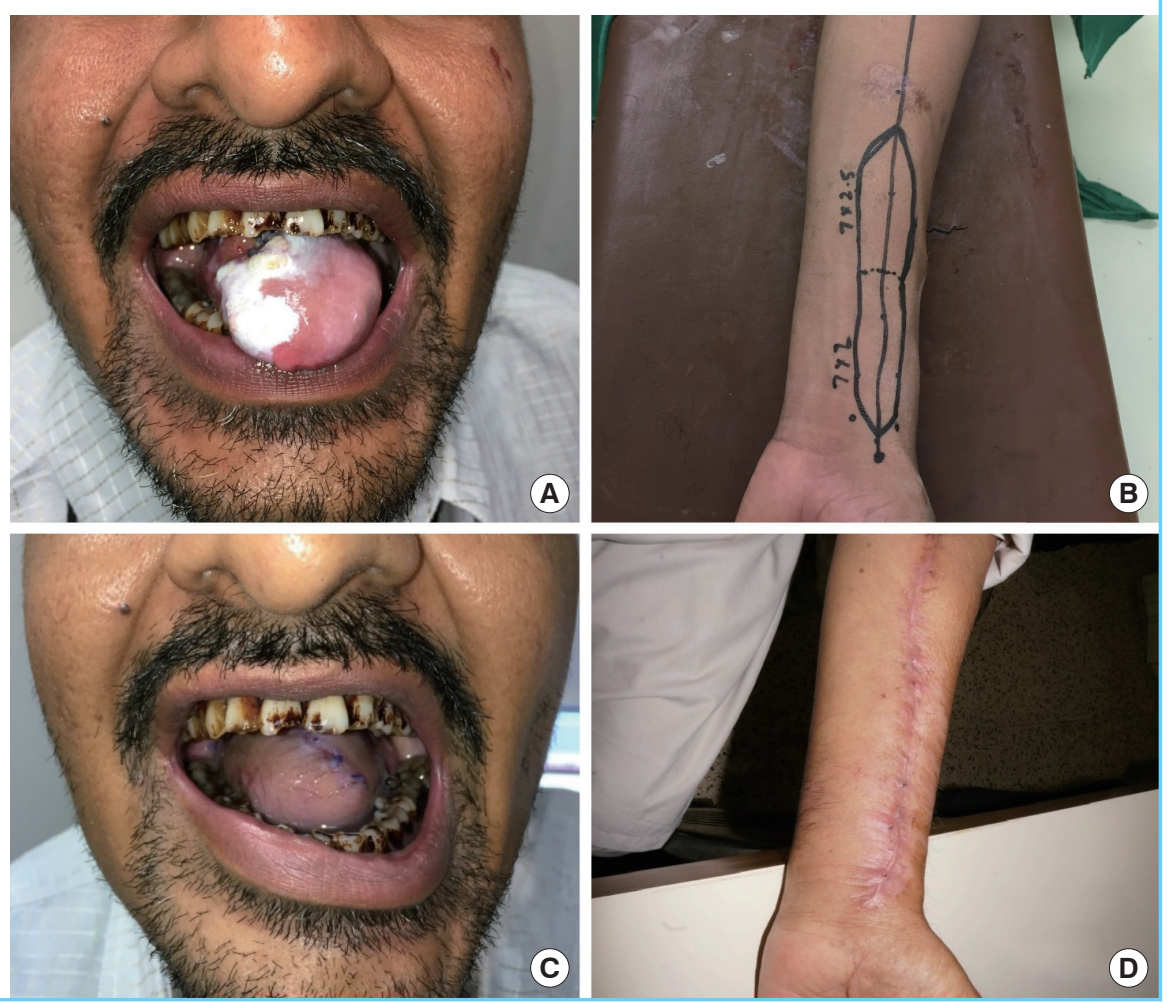
hypertrophic scar. The results are shown in Table 5. Motor function was excellent $(5 / 5)$ in the donor arm in 22 cases (91.7\%) and good (4/5) in two cases (8.3\%). All flaps were successful, and there were no cases of partial or complete loss. Some of the cases are shown in Figs. 2 and 3.

\section{DISCUSSION}

The radial forearm flap is a safe, reliable method for reconstructing most defects of the oral cavity. It is characterized by outstanding modelling ability, thinness, technically simple flap harvesting, and a long, wide-calibre vascular pedicle. This type of flap can be harvested concurrently with surgery in the oral and maxillofacial area with ease. and is the most commonly used type of free flap used in this area. A success rate over $95 \%$ is not uncommon at experienced centres, but there is still a small risk of flap compromise necessitating urgent re-exploration.

We found that by taking a narrow long flap, we were able to avoid grafting the donor site and could achieve direct closure, which avoided many complications. Richardson et al. [9], in their prospective study of 86 patients, reported that radial forearm flap donor site complications and morbidity included partial graft loss in 14 patients (16\%), tendon exposure in 11 patients (13\%), and delayed healing of the graft in 19 patients (22\%), while 21 patients (28\%) complained of poor aesthetic outcomes. Instead of raising a $4 \times 6 \mathrm{~cm}$ flap, which is done traditionally and requires skin grafting, a $2 \times 12 \mathrm{~cm}$ flap can be lifted and rolled back over as described. This provides the advantage of closing the donor site primarily, thereby avoiding many of the graft-related complications.

Furthermore, as the radial artery is very close to the skin in the distal forearm and has multiple cutaneous perforators in this region, as opposed to the relatively mobile proximal part where it is quite deep and has few perforators, the length of the pedicle is not usually a problem. To conclude, for small to medium-sized soft tissue defects, the nRFFF had acceptable outcomes due to its thinness, pliability, and major reduction in donor site aesthetic and functional morbidity.

\section{NOTES}

\section{Conflict of interest}

No potential conflict of interest relevant to this article was reported.

\section{Ethical approval}

The study was performed in accordance with the principles of the Declaration of Helsinki.

\section{Patient consent}

The patients provided written informed consent for the publication and the use of their images.

\section{ORCID}

Noman Shahzad https://orcid.org/0000-0001-8125-1554

\section{REFERENCES}

1. Yang GF, Chen PJ, Gao YZ, et al. Forearm free skin flap transplantation: a report of 56 cases. 1981. Br J Plast Surg 1997;50:162-5.

2. Urken ML, Weinberg H, Vickery C, et al. The combined sensate radical forearm and iliac crest free flaps for reconstruction of significant glossectomy-mandibulectomy defects. Laryngoscope 1992;102:543-58.

3. Swanson E, Boyd JB, Manktelow RT. The radial forearm flap: reconstructive applications and donor-site defects in 35 consecutive patients. Plast Reconstr Surg 1990;85:25866.

4. Kawashima T, Harii K, Ono I, et al. Intraoral and oropharyngeal reconstruction using a de-epithelialized forearm flap. Head Neck 1989;11:358-63.

5. Takato T, Harii K, Ebihara S, et al. Oral and pharyngeal reconstruction using the free forearm flap. Arch Otolaryngol Head Neck Surg 1987;113:873-9.

6. Soutar DS, Tanner NS. The radial forearm flap in the management of soft tissue injuries of the hand. Br J Plast Surg 1984;37:18-26.

7. Foucher G, van Genechten F, Merle N, et al. A compound radial artery forearm flap in hand surgery: an original modification of the Chinese forearm flap. Br J Plast Surg 1984;37: $139-48$.

8. Soutar DS, Scheker LR, Tanner NS, et al. The radial forearm flap: a versatile method for intra-oral reconstruction. $\mathrm{Br} \mathrm{J}$ Plast Surg 1983;36:1-8.

9. Richardson D, Fisher SE, Vaughan ED, et al. Radial forearm flap donor-site complications and morbidity: a prospective study. Plast Reconstr Surg 1997;99:109-15.

10. Toschka H, Feifel H, Erli HJ, et al. Aesthetic and functional results of harvesting radial forearm flap, especially with regard to hand function. Int J Oral Maxillofac Surg 2001;30: 42-8.

11. Nehrer-Tairych GV, Millesi W, Schuhfried O, et al. A comparison of the donor-site morbidity after using the prelaminated fasciomucosal flap and the fasciocutaneous radial forearm flap for intraoral reconstruction. Br J Plast Surg 2002;55:198-202. 
12. Werle AH, Tsue TT, Toby EB, et al. Osteocutaneous radial forearm free flap: its use without significant donor site morbidity. Otolaryngol Head Neck Surg 2000;123:711-7.

13. Brown MT, Cheney ML, Gliklich RL, et al. Assessment of functional morbidity in the radial forearm free flap donor site. Arch Otolaryngol Head Neck Surg 1996;122:991-4.

14. Brown MT, Couch ME, Huchton DM. Assessment of donor-site functional morbidity from radial forearm fasciocutaneous free flap harvest. Arch Otolaryngol Head Neck Surg 1999; 125:1371-4.

15. Suominen S, Ahovuo J, Asko-Seljavaara S. Donor site morbidity of radial forearm flaps: a clinical and ultrasonographic evaluation. Scand J Plast Reconstr Surg Hand Surg 1996;30: 57-61.

16. Lutz BS, Wei FC, Chang SC, et al. Donor site morbidity af- ter suprafascial elevation of the radial forearm flap: a prospective study in 95 consecutive cases. Plast Reconstr Surg 1999;103:132-7.

17. Bardsley AF, Soutar DS, Elliot D, et al. Reducing morbidity in the radial forearm flap donor site. Plast Reconstr Surg 1990;86:287-92.

18. Timmons MJ, Missotten FE, Poole MD, et al. Complications of radial forearm flap donor sites. Br J Plast Surg 1986; 39:176-8.

19. Sardesai MG, Fung K, Yoo JH, et al. Donor-site morbidity following radial forearm free tissue transfer in head and neck surgery. J Otolaryngol Head Neck Surg 2008;37:411-6.

20. Singer AJ, Arora B, Dagum A, et al. Development and validation of a novel scar evaluation scale. Plast Reconstr Surg 2007; 120:1892-7. 